\title{
The impact of depression and anxiety treatment on biological aging and metabolic stress: study protocol of the Mood treatment with antidepressants or running (MOTAR) study
}

Bianca A. Lever-van Milligen ${ }^{1,2^{*}}$ (D), Josine E. Verhoeven ${ }^{1,2}$, Lianne Schmaal ${ }^{1,2}$, Laura S. van Velzen ${ }^{1,2}$, Dóra Révész ${ }^{1,2}$, Catherine N. Black ${ }^{1,2}$, Laura K. M. Han ${ }^{1,2}$, Melany Horsfall ${ }^{1,2}$, Neeltje M. Batelaan ${ }^{1,2}$, Anton J. L. M. van Balkom ${ }^{1,2}$, Digna J. F. van Schaik ${ }^{1,2}$, Patricia van Oppen ${ }^{1,2}$ and Brenda W. J. H. Penninx ${ }^{1,2}$

\begin{abstract}
Background: Depressive and anxiety disorders have shown to be associated to premature or advanced biological aging and consequently to adversely impact somatic health. Treatments with antidepressant medication or running therapy are both found to be effective for many but not all patients with mood and anxiety disorders. These interventions may, however, work through different pathophysiological mechanisms and could differ in their impact on biological aging and somatic health. This study protocol describes the design of an unique intervention study that examines whether both treatments are similarly effective in reducing or reversing biological aging (primary outcome), psychiatric status, metabolic stress and neurobiological indicators (secondary outcomes).

Methods: The MOod Treatment with Antidepressants or Running (MOTAR) study will recruit a total of 160 patients with a current major depressive and/or anxiety disorder in a mental health care setting. Patients will receive a 16week treatment with either antidepressant medication or running therapy (3 times/week). Patients will undergo the treatment of their preference and a subsample will be randomized (1:1) to overcome preference bias. An additional no-disease-no-treatment group of 60 healthy controls without lifetime psychopathology, will be included as comparison group for primary and secondary outcomes at baseline. Assessments are done at week 0 for patients and controls, and at week 16 and week 52 for patients only, including written questionnaires, a psychiatric and medical examination, blood, urine and saliva collection and a cycle ergometer test, to gather information about biological aging (telomere length and telomerase activity), mental health (depression and anxiety disorder characteristics), general fitness, metabolic stress-related biomarkers (inflammation, metabolic syndrome, cortisol) and genetic determinants. In addition, neurobiological alterations in brain processes will be assessed using structural and functional Magnetic Resonance Imaging (MRI) in a subsample of at least 25 patients per treatment arm and in all controls.

\footnotetext{
*Correspondence: b.lever@ggzingeest.nl; B.Lever@ggzingeest.nl

'Amsterdam UMC, Vrije Universiteit, Psychiatry, Amsterdam Public Health

Research Institute, Amsterdam, The Netherlands

${ }^{2}$ GGZ inGeest Specialized Mental Health Care, Amsterdam, The Netherlands
} 
(Continued from previous page)

Discussion: This intervention study aims to provide a better understanding of the impact of antidepressant medication and running therapy on biological aging, metabolic stress and neurobiological indicators in patients with depressive and anxiety disorders in order to guide a more personalized medicine treatment.

Trial registration: Trialregister.nl Number of identification: NTR3460, May 2012.

Keywords: Depression, Anxiety, Treatment, Antidepressant, SSRI, Running therapy, Aging, Telomere length, Telomerase activity, Inflammation, Metabolic syndrome, Cortisol, fMRI

\section{Background}

Depressive and anxiety disorders are common comorbid conditions with a large impact on public health $[1,2]$. Meta-analyses show that persons with depressive and anxiety disorders have increased risks for the onset of cardiovascular diseases, diabetes, stroke, obesity [3], and advanced physical [3, 4] and cognitive decline [5]. In other words, depressive and anxiety disorders need to be considered as an important risk factor for a multitude of agingrelated conditions. Dysregulation of physiological stress systems such as inflammation, hyperactivity of the HPAaxis and metabolic dysregulation [6, 7] have been suggested to partly underlie these associations. Additionally, persons with depressive and anxiety disorders are found to be subject to advanced biological aging. Furthermore, these physiological stress systems may also play a role in recovery mechanisms of depression and anxiety disorders.

Two treatment regimens for depressive and anxiety disorders that have shown to be effective are antidepressants and running therapy [8-11]. It is, however, unclear whether they could beneficially affect biological aging and physiological stress-systems dysregulations. Well-designed studies looking into the underlying physiological pathways of both treatments are lacking. It has been suggested that these interventions may work through different pathophysiological mechanisms. Despite their comparable effectiveness on mental health outcomes [8], running therapy may have a more beneficial impact on somatic health indicators including biological aging [12]. This intervention study examines and compares the impact of antidepressant medication and running therapy on biological aging, metabolic stress and neurobiological abnormalities related to depression and anxiety.

\section{Depressive and anxiety disorders and biological aging}

In line with their negative impact on a multitude of agingrelated somatic conditions, depression and anxiety disorders have found to be related to more advanced biological aging. This is for instance evidenced by shorter telomeres found in depression and/or anxious patients as compared to healthy controls [13-16]. Telomere length (TL), a relatively wellstudied marker of cellular age, integrates the cumulative lifetime burden of genetic and environmental factors dependent on chronological age [17], and predicts several aging-related diseases and early mortality [18]. Telomeres are tandem repeated DNA sequences that form protective caps at chromosome ends [19] which can be elongated by telomerase enzymes. High telomerase activity has protective functions for aging and cell death and lower telomerase activity is linked to aging-related disease factors [20-22]. Some studies suggest that telomerase activity is elevated in the presence of a depression diagnosis [23], possibly as an attempt to compensate for the loss of TL. However, another study found decreased telomerase activity in a chronically stressed sample [24], leaving it unclear whether increased activity of the enzyme is a sign of improved health or rather a compensatory mechanism. The extent to which depression and anxiety treatment impacts the telomere/ telomerase system has not been extensively examined [25].

\section{Depressive and anxiety disorders, metabolic stress and neurobiological abnormalities}

In various studies and meta-analyses, depressive and anxiety disorders have been linked to physiological alterations of central bodily stress systems: systemic inflammation $[7$, 26, 27] and oxidative stress [6], hyperactivity of the hypothalamus-pituitary adrenal (HPA) axis [28], a dysregulated autonomic tone $[29,30]$ accompanied with metabolic syndrome dysregulations [31]. Metabolic and physiological stress system dysregulations could contribute to the process of advanced biological aging as they have shown to affect TL and the telomere maintenance system [32-34].

Physiological stress systems also impact the structural and functional integrity of the brain, such as hippocampal volume, prefrontal cortex (PFC) morphology, and activity of the amygdala, insula and anterior cingulate cortex (ACC) [35-38], albeit inconsistently [39]. These are key brain regions implicated in depression and anxiety as there is converging evidence for widespread but subtle structural alterations in prefrontal regions such as the ACC, dorsomedial and orbitofrontal cortex, posterior cingulate cortex, insula, and the hippocampus [40-45]. There is also some evidence for rostral ACC, amygdala and medial PFC hyperactivation during emotional processing, while dorsal regions may be hypoactive in people with depression or anxiety disorders [46-49], although findings have been inconsistent across studies [50]. 


\section{Depressive and anxiety disorder treatment and physiological changes}

Commonly prescribed selective serotonin re-uptake inhibitors (SSRI) have shown to be effective in depression and anxiety treatment $[9,51]$. Some -although limited- evidence exists suggesting that SSRI treatment results in decreased cortisol [52], inflammatory [53] and antioxidant [54] levels. A recent review suggested a role for telomerase activity mediating the beneficial effects of antidepressants medication [55], possibly by promoting cell survival and/or function both in the brain and in the periphery. Only a few studies examined the association between antidepressant treatment and the telomere system and found shorter leukocyte telomere length (LTL) in patients who did not respond to antidepressants compared to those who did respond [56, 57]. Sample sizes of above-mentioned studies were relatively small, thus associations between antidepressant response and telomere length/telomerase activity remain to be extensively explored.

A similarly effective intervention is running therapy [10, 58, 59]. Running therapy works through the direct impact of aerobic exercise on opioid [60,61], monoaminergic mechanisms [62] and regional cerebral blood flow [63]. The impact of running therapy has also been shown to reduce oxidative stress [64], inflammation [65-67], and cortisol [68]. Exercise has also shown to have beneficial impact on TL in a cancer population with higher telomerase activity emerging after 3 months of exercise, which was paralleled by decreases in psychological distress [69], a finding confirmed in other research [12, 70-72]. Two studies comparing running therapy and SSRI treatment confirmed a similar effectiveness for depression $[8,73]$ and anxiety disorders [74]. Nevertheless, these interventions probably work through different pathophysiological mechanisms and may have different impact on biological aging.

\section{Objective}

This intervention study examines and compares the impact of antidepressant medication and running therapy on biological aging (primary outcome) and psychiatric status, metabolic stress and neurobiological abnormalities relevant for depression and anxiety disorders (secondary outcomes). This study also examines to what extent treatment-induced improvement in psychiatric status parallels with improvement of biological aging, metabolic stress and neurobiological abnormalities. Furthermore, this study compares the pre- and posttreatment outcomes to the physiological stress parameters of the no-disease-no-treatment control group.

\section{Methods \\ Study design}

The MOod Treatment with Antidepressant or Running (MOTAR) study is a 16-week intervention study with two treatment arms: 1) antidepressant medication and 2) running therapy (see Fig. 1). In total, 160 patients with a depressive and/or anxiety disorder receive antidepressants or running therapy. Depressive and anxiety disorders are highly comorbid [75], also over time [76, 77], their underlying pathophysiology is largely comparable and both disorders are treated with similar treatments $[10,51,74,78]$. A randomised controlled trial is the preferred method to compare two interventions, but also comes with limitations: quite some patients do not agree with random treatment assignment, and therefore, studies may result in selective inclusion of subjects which hampers the generalizability of results. Consequently, we decided to conduct a pragmatic study (resembling a partially randomised preference patients design (PRPP) [79]. First, patients without strong preference for treatment allocation are randomly allocated (1:1) to either antidepressant medication or running therapy. The SPSS random generator (SPSS, version 20.0) is used to randomise these participants. Subsequently, persons who were not willing to be randomised but are willing to participate in the study, were allocated to their preferred intervention. In order to be certain that no age differences arise, randomization is stratified by age in two groups (cut

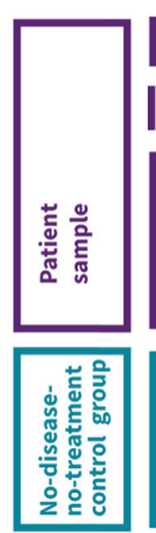

Treatment with antidepressants or running therapy
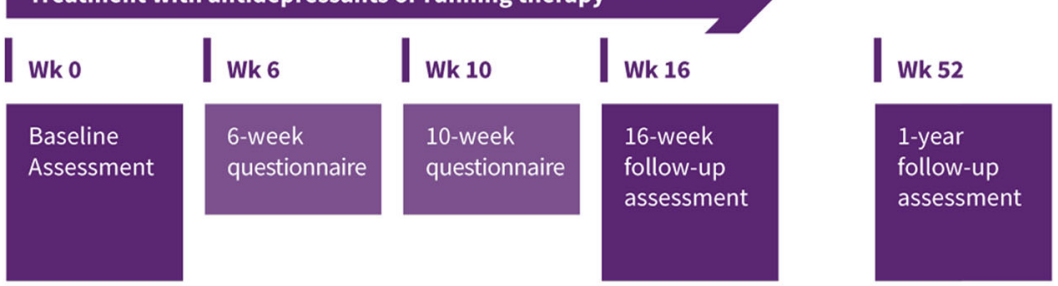

Baseline

Assessment

Fig. 1 MOTAR flowchart 
off 40 years). Further, in a subset of at least 50 subjects ( 25 from both treatment conditions) neuroimaging (Magnetic Resonance Imaging (MRI) data will be collected. A nodisease-no-treatment-control group $(N=60)$ will be examined to compare health, physiological and neurobiological indicators between persons with and without depression and anxiety disorders at baseline, and allows checks on whether improvements over time after treatment completely restores health and physiological levels to those of healthy controls.

\section{Recruitment and study settings}

Between 2012 and 2019, patients are recruited when (newly) enrolled at GGZ inGeest (mental health organization in the surroundings of Amsterdam, The Netherlands) with depressive and/or anxiety disorders. Patients receive information about the study during the intake and are asked for their participation. During a telephone screening, in- and exclusion criteria are checked and when consent is given, patients undergo a baseline assessment before starting their treatment. All patients are also asked to participate in the MRI study substudy.

The no-disease-no-treatment-control group is recruited through advertisements in the area and through the website www.motar.nl. Persons receive information about the study and are asked for their participation. Patients and controls are matched on the basis of age, sex and educational level. In- and exclusion criteria are checked and after given consent, the healthy persons only undergo a baseline and neuroimaging assessment.

\section{Eligibility criteria}

Inclusion criteria of the patient sample include: having a current depressive disorder (major depressive disorder) or anxiety disorder (social phobia, generalized anxiety disorder, panic disorder with or without agoraphobia) as ascertained by the Diagnostic and Statistical Manual of Mental Disorders - Fourth edition (DSM-IV) algorithms with the CIDI (Composite International Diagnostic Interview) [80] and being aged between 18 and 70 years. Exclusion criteria are: 1) use of antidepressants in last 2 weeks, 2) current use of other psychotropic medication, except for the use of benzodiazepines with stable usage, 3 ) regular exercising more than once a week, 4) primary severe, clinically diagnosed psychiatric diagnosis other than a depressive or anxiety disorder, 5) evidence of acute suicidal risk (based on clinical view), 6) medical contra-indications to running therapy or antidepressants (e.g. serious heart problems) as confirmed by the patient's physician, and 7) being pregnant.

Inclusion criteria of the no-disease-no-treatment-control group are having a negative lifetime history of psychiatric disorders as checked with the CIDI and being aged between 18 and 70 years. Exclusion criteria are: 1) participation in regular (>1/week) exercise and 2 ) medical contra-indications to running therapy or antidepressants (e.g. serious heart problems) as confirmed by a physician.

Additional exclusion criteria for the MRI sub-study are major internal or neurological disorders, pregnancy and known contra-indications for MRI investigations, such as the presence of metal objects (e.g. pacemaker, arteriovenous clips) or claustrophobia.

\section{Consent procedure, baseline and follow-up assessments} Informed consent approved by the Medical Ethical Committee VU University Medical Centre has to be signed before starting the baseline assessment. During a 4-h faceto-face baseline assessment a wide range of data will be collected, including demographic information, a diagnostic psychiatric interview, a medical examination, a cycle ergometer test, collection of saliva, urine, and blood and various self-reported clinical questionnaires. At week 6 and week 10 depression and anxiety symptom severity will be assessed by self-report questionnaires. At week 16 and week 52, the assessments will be repeated in the patient sample (see Fig. 1). For each face to face assessment, the patient will receive a gift voucher of $€ 50$. MRI measurements consist of a clinical interview and a neuroimaging session with a total duration of approximately $2.5 \mathrm{~h}$. For each MRI measurement, the patient will receive a gift voucher of $€ 25$-. The control group will undergo a baseline and neuroimaging assessment, but no follow-up assessments. The control participants will receive a gift voucher of $€ 50$. Table 1 gives an overview of the data collection.

\section{Intervention}

Participants will undergo an intervention of 16 weeks since this period has shown to be sufficient to decrease depressive and anxiety symptoms and to impact on physiological stress after antidepressant therapy [101] or running therapy $[102,103]$.

\section{Antidepressant medication}

Patients will receive standardized treatment with escitalopram, a selective serotonin reuptake inhibitor (SSRI) which has documented efficacy, a rather favorable side effect profile, is recommended as first-step treatment in both the General Practitioner (NHG Standardized depressive disorder and anxiety disorder (in Dutch)) and Psychiatry treatment guidelines (Multidisciplinary guidelines depression and anxiety (in Dutch)), and is one of the most commonly prescribed antidepressants [101, 104]. An initial dosage of $10 \mathrm{mg}$ per day of escitalopram is used. Medication management is provided by a psychiatrist who meets each patient at study onset and at weeks 2, 6, 10 and 16. At these meetings, the psychiatrist evaluates treatment response and side effects, and titrates dosage (to a maximum of $20 \mathrm{mg}$ ) according to the multidisciplinary depression/anxiety guidelines until a clinically effective 
Table 1 Collected information on central (mental) health outcomes in MOTAR

\begin{tabular}{|c|c|c|c|c|c|c|c|}
\hline & Instrument & Method & $\begin{array}{l}\text { Week } \\
0\end{array}$ & $\begin{array}{l}\text { Week } \\
6\end{array}$ & $\begin{array}{l}\text { Week } \\
10\end{array}$ & $\begin{array}{l}\text { Week } \\
16\end{array}$ & $\begin{array}{l}\text { Week } \\
52\end{array}$ \\
\hline \multicolumn{8}{|l|}{ Primary outcomes } \\
\hline $\begin{array}{l}\text { Biological aging: telomere length, } \\
\text { telomerase activity }\end{array}$ & Fasting blood samples & Blood & $x$ & - & - & $x$ & $x$ \\
\hline \multicolumn{8}{|l|}{ Secondary outcomes } \\
\hline \multicolumn{8}{|l|}{ Biological and general health indicators } \\
\hline $\begin{array}{l}\text { Biomarkers (inflammation, metabolic } \\
\text { syndrome) }\end{array}$ & Fasting blood samples & Blood & $x$ & - & - & $x$ & $x$ \\
\hline Gene-expression (RNA) & Fasting blood samples & Blood & $x$ & - & - & $x$ & $x$ \\
\hline HPA-axis (cortisol) & 2 days of 6 saliva samples & Saliva & $x$ & - & - & $x$ & $x$ \\
\hline Oxidative stress & Urine sample & Urine & $x$ & - & - & $x$ & $x$ \\
\hline Autonomic nervous system & $\begin{array}{l}\text { Electro + impedance cardiography, heart rate } \\
\text { variability [81] }\end{array}$ & ME & $x$ & - & - & $x$ & $x$ \\
\hline Blood pressure & Systolic and diastolic BP & ME & $x$ & - & - & $x$ & $x$ \\
\hline Body composition & Weight, height, waist+ hip circumfereence & ME & $x$ & - & - & $x$ & $x$ \\
\hline Physical condition & Astrand sub max test [82] & ME & $x$ & & - & $x$ & $x$ \\
\hline Muscle strength & Hand grip strength [81] & ME & $x$ & - & - & $x$ & $x$ \\
\hline Lung function & Peak expiratory flow [82] & ME & $x$ & - & - & $x$ & $x$ \\
\hline Pain & Chronic graded pain scale [83] & Int & $x$ & - & - & $x$ & $x$ \\
\hline Somatization & Short somatization questionnaire [84] & SR & $x$ & - & - & $x$ & $x$ \\
\hline Disability severity & WHO-DAS II [85] & SR & $x$ & - & - & $x$ & $x$ \\
\hline \multicolumn{8}{|l|}{ Depressive and anxiety disorders } \\
\hline Presence of MDD & CIDI: MDD [78] & Int & $x$ & - & - & $x$ & $x$ \\
\hline Presence of anxiety dis & CIDI: SocPhob, Agora, GAD, PA [78] & Int & $x$ & - & - & $x$ & $x$ \\
\hline Course of symptoms & Life-chart [86] & Int & $x$ & - & - & $x$ & $x$ \\
\hline Severity of depression & Inventory of depressive symptoms [87] & $S R$ & $x$ & $x$ & $x$ & $x$ & $x$ \\
\hline Severity of anxiety & Beck anxiety index [88] and Fear questionnaire [89] & SR & $x$ & $x$ & $x$ & $x$ & $x$ \\
\hline Sleep & Insomnia Rating Scale [90] & Int & $x$ & - & - & $x$ & $x$ \\
\hline \multicolumn{8}{|c|}{ Descriptive variables, potential confounding covariates and potential mediating variables } \\
\hline Age, gender, ethnicity & Standard questions & Int & $x$ & - & - & - & - \\
\hline Socio-economic status & Education, income, occupation & Int & $x$ & - & - & - & - \\
\hline Physical activity & SQUASH questionnaire [91] & SR & $x$ & - & - & $x$ & $x$ \\
\hline Smoking & Past + current smoking questions & SR & $x$ & - & - & - & $x$ \\
\hline Medication use & Drug container observation & Int & $x$ & - & - & $x$ & $x$ \\
\hline Regular alcohol intake & AUDIT questionnaire [92] & SR & $x$ & - & - & - & $x$ \\
\hline Somatic diseases & Presence + symptoms of disease & Int & $x$ & - & - & $x$ & $x$ \\
\hline Health care & Perceived need of care [93] & Int & $x$ & - & - & $x$ & $x$ \\
\hline Work and disability & Tic-P questionnaire [94] & Int & $x$ & - & - & $x$ & $x$ \\
\hline Personality & NEO-FFI questionnaire [95] & SR & $x$ & - & - & $x$ & $x$ \\
\hline Locus of control & Pearlin \& Schooler mastery scale [96] & SR & $x$ & - & - & $x$ & $x$ \\
\hline Depression vulnerability & LEIDS-R questionnaire [97] & SR & $x$ & - & - & $x$ & $x$ \\
\hline Anxiety vulnerability & Anxiety senstivity index [98] & SR & $x$ & - & - & $x$ & $x$ \\
\hline Experimental cognitive task & Implicit association test (IAT) [99] & $C T$ & $x$ & - & & $x$ & $x$ \\
\hline Experimental memory task & Digit Span (WAIS) [100] & Int & $x$ & - & - & $x$ & $x$ \\
\hline Important neg + pos life events & Brugha questionnaire [101] & Int & $x$ & - & - & $x$ & $x$ \\
\hline
\end{tabular}


Table 1 Collected information on central (mental) health outcomes in MOTAR (Continued)

\begin{tabular}{|c|c|c|c|c|c|c|c|}
\hline & Instrument & Method & $\begin{array}{l}\text { Week } \\
0\end{array}$ & $\begin{array}{l}\text { Week } \\
6\end{array}$ & $\begin{array}{l}\text { Week } \\
10\end{array}$ & $\begin{array}{l}\text { Week } \\
16 \\
\end{array}$ & $\begin{array}{l}\text { Week } \\
52\end{array}$ \\
\hline Childhood Trauma & Youth Trauma questionnaire [102] & SR & $x$ & - & - & - & - \\
\hline Familiy history & Familiy history inventory & Int & $x$ & - & - & - & - \\
\hline \multicolumn{8}{|l|}{ Neuroimaging assessment (subsample) } \\
\hline Verbal episodic memory & 15 -words test [103] & MRI & $x$ & - & - & $x$ & $x$ \\
\hline Task-related brain activity & $\begin{array}{l}\text { Emotional face matching paradigm and N-back } \\
\text { paradigm [104] }\end{array}$ & $\mathrm{MRI}$ & $x$ & - & - & $x$ & $x$ \\
\hline Brain network connectivity & Resting state MRI images & MRI & $x$ & - & - & $x$ & $x$ \\
\hline \multicolumn{8}{|l|}{ Process indicators (intervention adherence) } \\
\hline \multicolumn{8}{|c|}{ Exercise intervention group: Exercise participation and heart rate will be administrated during each session.. } \\
\hline \multirow[t]{2}{*}{ Antidepressant intervention group } & Side effect medication questionnaire & Int & - & $x$ & x & $x$ & - \\
\hline & Adherence (pill count) & Int & - & $x$ & $x$ & $x$ & - \\
\hline
\end{tabular}

SR self-report, Int interview, Blood data collection via fasting blood sample, CT computer task, ME medical examination

dosage is achieved. Following the medication protocol, if the initial SSRI is poorly tolerated, the psychiatrist can switch prescription to another SSRI drug (sertraline, dosage of $50 \mathrm{mg}$ to a maximum of $150 \mathrm{mg}$ ). Adherence to treatment is evaluated by a patient's diary and administration $\log$ by the psychiatrist. After 16 weeks of treatment, a research assessment will take place and further treatment is conducted following clinical guidelines.

\section{Running therapy}

Therapy consists of three 45-min outdoor running sessions per week, in line with the public health recommendations by $\mathrm{CDC} /$ American College of Sports Medicine [105] and its earlier successful effects on depression and anxiety $[74,106]$. Patients will be gradually assigned individual training ranges equivalent to $70-85 \%$ of their heart rate reserve, calculated from the heart rate achieved during a cycle ergometer test with the formula of Karvonen [107]. This intensity level was confirmed to be effective in decreasing depressive symptoms [103]. During the screening phase and during baseline assessment, so before formal inclusion to the study, potential physical and/or somatic problems and use of medication are administrated. When serious somatic conditions are signalled, the person's own physician will be contacted and consulted in order to discuss potential study participation. Furthermore, at the beginning of the running intervention, the running therapist discusses experience of exercise in the past, and will provide information about food, moisture balance, fatigue, injuries, sleep and recovery. The running therapy intervention was conducted at a medical institution (GGZinGeest) where there is always a physician approachable.. Running sessions will be organized and supervised by qualified staff, starting with a 10-min warming-up exercise period followed by $30 \mathrm{~min}$ of jogging at an intensity that maintains heart rate within the assigned training range (starting in the first 4 weeks at $50-70 \%$ of heart rate reserve and in the subsequent 12 weeks at $70-85 \%$ of heart rate reserve), finishing with $5 \mathrm{~min}$ of cooling-down exercises. During the running sessions, all subjects wear a heart rate monitor. Heart rate will be confirmed three times per session to ensure that patients are exercising within the prescribed exercise training ranges. Data of the heart rate monitor will be uploaded after sessions and used to encourage study compliance. Patients are stimulated to participate in all three organized group sessions, but if strongly preferred, home-based individual running is allowed once per week. The trainer monitors training attendance. The size of the running group is on average 5 or 6 patients. Both interventions were conducted using evidence-based clinical guidelines (https:// www.nhg.org/sites/default/files/content/nhg_org/uploads/multidisciplinaire_richtlijn_depressie_3e_revisie_2 013.pdf). Adverse events in both treatment programs will be signalled and reported the medical ethical committee. After 16 weeks of treatment, a research assessment will take place and further treatment is conducted following clinical insights by the responsible clinician.

\section{Outcomes \\ Primary outcomes}

The primary outcome of this trial is the change in biological aging, measured through TL and telomerase activity before the start and at the end of the intervention. TL has been shown to be correlated to functioning of multiple physiological stress systems such as the immuneinflammatory system, the hypothalamus-pituitary-adrenal (HPA)-axis and the autonomic nervous system (ANS) [33, 34] and therefore picks up potential improvement in various underlying mechanisms. In addition, TL has been shown to be predictive of various somatic health outcomes 
including mortality. TL has earlier been used in studies examining the effects of lifestyle interventions [72, 108, 109] and has shown sensitive to change, even at rather short term, interventions were linked to less shortening of TL. In addition to explore the underlying telomere system dynamics, we also will measure telomerase activity, as was done in Wolkowitz et al. (2012) [23]. TL will be measured from purified DNA samples from peripheral blood mononuclear cells that were stored frozen at $-80^{\circ} \mathrm{C}$ using a quantitative polymerase chain reaction (qPCR)-based assay. Telomerase enzymatic activity will be measured by the Telomerase Repeat Amplification Protocol (TRAP149) using the commercial TRAPeze kit (Chemicon, Upstate/CHEMICON, Temecula, CA, USA) [23]. Less shortening of TL after treatment will be seen as reverse of biological aging.

\section{Secondary outcomes}

Biological and general health indicators Biomarkers of physiological health will be gathered through fasting blood samples, 24-h urine, and six saliva samples were taken at 1 day covering morning awakening response (at awakening and at 30, 45 and $60 \mathrm{~min}$ later), afternoon (at $6 \mathrm{pm}$ ) and evening levels (at $10 \mathrm{pm}$ ) to e.g. examine inflammatory markers, cortisol levels, metabolic syndrome abnormalities, DNA and oxidative stress. Activity of the autonomic nervous system will be measured using the ambulatory monitoring system (VU-ams) of which reliability and recording methodology have been described previously [110]. Furthermore, blood pressure, fitness (using bicycle ergometer with the Astrand method [111]), hand grip strength (by Jamar hand grip meter) [112] and lung function (using Mini Wright peak flow meter) [113] will be tested. The chronic graded pain scale [114] will be taken to evaluate pain, somatization will be assessed with the short somatization scale [115] and disability severity will be gathered using the WHODAS II [116].

Depressive and anxiety disorders The presence of depressive disorders (Major Depressive Disorder) and anxiety disorders (social phobia, generalized anxiety disorder, panic disorder and agoraphobia) will be established using the CIDI. The CIDI is a valid and reliable instrument to assess depressive and anxiety disorders [80] and will be administered by specially trained research staff. The type and number of depressive and anxiety disorders will be compared across the intervention groups and, if necessary, these clinical characteristics will be considered as covariates in the main analyses. Fluctuation of depression and anxiety during follow-up will be examined using the Lifechart method [81]. Severity of depression is measured using the 30-item Inventory of Depressive Symptomatology (IDS-SR30) [82]. Severity of anxiety is measured with the 21-item Beck
Anxiety Inventory (BAI) [83]. For both scales higher scores mean higher symptom severity. Phobia symptoms will be measured with the Fear Questionnaire [84]. Sleep duration and quality will be examined with the Insomnia Rating Scale [85]. Psychotropic medication use was assessed during the interview at baseline, 16 and 52 weeks by inspection of the participant's medication containers. It contained lifetime history of use as well as use during the study and was classified using the World Health Organization Anatomic Therapeutic Chemical (ATC) classification (World Health Organization Centre for Drug Statistics Methodology, 2010).

Descriptive variables, potential confounding covariates and potential mediating variables Lifestyle indicators, (change in) health care status and utilization, personality and cognitive vulnerability, and personal history are also considered as mediating variables. The SQUASH questionnaire [86] will be taken to examine daily-life physical activities. Questions of smoking and drug use will be asked during the interview and the Audit questionnaire [87] will be used to measure regular alcohol intake. A chronic disease inventory and the Perceived Need for Care Questionnaire will be used to assess (changes in) health and health care use [88]. Loss of productivity at work and health care utilization will be gathered with the TIC-P [89]. Personality and cognitive vulnerability traits will be measured using the NEO-FFI questionnaire [90], personal mastery questionnaire [91], the Leids-R questionnaire [92], and the Anxiety Sensitivity Index (ASI) [93]. The Implicit association test (IAT) [94] will be used as experimental cognitive emotional task and the Digit Span (WAIS) [95] as an experimental memory task to assess working memory. Personal history contains assessment of important negative life events with the Brugha questionnaire [96], childhood trauma with the childhood trauma questionnaire [97], and family history of psychiatric disorders will be gathered by specific questions.

Neuroimaging assessment In a subsample of the patients and in the healthy controls a neuroimaging assessment will be taken using the $3 \mathrm{~T}$ Philips Intera MR system. The 15-words test, a Dutch version of the Rey's auditory verbal learning test [98] will be performed outside the scanner to assess verbal episodic memory.

Anatomical T1-weighted and diffusion tensor imaging (DTI) scans will be obtained to assess grey and white matter structure. An emotional face matching paradigm [99] and N-back paradigm [100] will be employed to examine task-related brain activity. Finally, brain network connectivity will be examined during rest by acquiring resting state fMRI images. 


\section{Sample size}

Published running therapy and antidepressant intervention studies in non-psychiatric groups have yielded effect sizes for changes in biological aging ranging from 0.5 [74] to 1.2 [112]. When using the minimum effect size found (0.5), $80 \%$ power and $p=0.05$, we need 63 subjects per group. Considering a dropout of $20 \%, n=76$ patients per group are needed to illustrate significant antidepressant and running therapy effects on biological aging in a patient group. That is why we strive for 80 patients per group, and 160 total.

As described by Thirion, functional MRI analyses require a minimum of 25 subjects per group for adequate statistical power [117]. In addition, we aimed to include 60 healthy controls to allow additional comparisons in outcomes between controls and patients.

\section{Organisation, and quality insurance and data management}

Compliance with antidepressant medication or running therapy is assessed using patient's and therapeutic logs. Patients who withdraw from the intervention will be asked reason(s) for drop out and they will be motivated to continue the measurements with the purpose to minimize loss of follow-up data and to make the intention to treat analysis and per-protocol analysis possible.

Research data will be collected by a coded participant number. Interviews will be conducted by computer and questionnaires by paper and will be entered into the system by the research assistant. An administrative database will be used to ensure timely assessments. The data manager will make back-ups for the monitoring of overall progress and data quality.

\section{Statistical analysis plan}

Missing data will be inspected and handled via full information maximum likelihood. Mixed model regression analyses will be conducted to estimate the effect size of both.

Interventions on biological aging and psychiatric status, metabolic stress and neurobiological abnormalities. Per protocol analyses within intervention groups will be conducted to evaluate whether change of biological aging and metabolic stress is a function of protocol adherence. The two intervention groups will be compared using mixed models or generalized estimating equations (GEE) to assess the longitudinal change of biological aging, physiological and metabolic stress and psychiatric symptoms. These models will also compare physiological and clinical effects of those who are willing and not willing to be randomised to check the impact of a patients' preferred or allocated intervention. Furthermore, preand posttreatment outcomes to physiological stress parameters will be compared to the no-disease-no-treatment control group using regression analyses.

\section{Trial status}

The MOTAR study was approved by the Medical Ethics Committee of the VU University Medical Center Amsterdam and registered with the Netherlands Trial Register under NTR3460. Recruitment commenced in September 2012 and is ongoing.

\section{Discussion}

A wide range of treatment programs for depressive and anxiety disorders are available but it remains largely unknown whether the impact of these programs on biological aging, metabolic stress and neurobiological abnormalities are comparable. Treatment with antidepressant medication or running therapy have both shown to be effective in depression and anxiety, but a well-designed comparative study of these treatment strategies and their impact on physiological and neurobiological processes is currently lacking. As the number and type of clinician contacts between groups are not similar, this could be underlying clinical improvement. However, the interventions in this trial were developed in line with current guideline standards and therefore are as much as possible reflective of regular clinical care treatments.

This intervention study is designed to examine and compare the impact of antidepressant medication and running therapy on changes of both mental and physiological health, including biological aging, metabolic stress and neurobiological function and whether these pre- and posttreatment outcomes are comparable with persons without a psychiatric status. It is expected that this study provides more detailed information about underlying biological mechanisms of depression and anxiety treatment effects. Having insight in the favourable physiological stress effects of these treatment regimens could probably also be helpful in increasing the effectiveness of personalised medicine.

\section{Abbreviations}

ACC: Anterior cingulate cortex; Agora: Agoraphobia; ASI: Anxiety sensitivity index; BAl: Beck's anxiety index; BP: Blood pressure; CDC: Center for disease control; CIDI: Composite international diagnostic interview; CT: Computer task; DSM-IV: Diagnostic and statistical manual of mental disorders fourth edition; DTI: Diffusion tensor imaging; GAD: Generalised anxiety disorder; HPA: Hypothalamus-pituitary adrenal; IAT: Implicit association task; IDSSR: Inventory of depressive symptomatology; LTL: Leukocyte telomere length; MDD: Major depressive disorder; ME: Medical examination; MOTAR: Mood treatment with antidepressants or running; MRI: Magnetic resonance imaging; NEO-FFI: Neuroticism- extraversion-openness five-factor inventory; NHG: Nederlands huisartsen genootschap; PA: Panic disorder; PFC: Prefrontal cortex; qPCR: Quantitative polymerase chain reaction; SocPhob: Social phobia; SPSS: Statistical package for social sciences; SQUASH: Short questionnaire to assess health enhancing physical activity; SR: Self-report; SSRI: Selective serotonin re-uptake inhibiters; TIC-P: Treatment inventory of costs in patients; TL: Telomere length; TRAP: Telomerase repeat amplification protocol; VU-ams: VU university ambulatory monitoring system; WAIS: Wechsler adult intelligence scale; WHODAS: World health organisation disability assessment schedule 


\section{Authors' contributions}

BP designed and got funding for the study. PO, DS, AB, NM, LM contributed to the conception of the study. BL coordinated the recruitment of patients and the data collection. $\mathrm{LS}, \mathrm{DR}, \mathrm{CB}, \mathrm{LH}$, and $\mathrm{MH}$ helped conducting the study. BL and JV drafted the first manuscript. PO, DS, AB, NM, LM, LS, DR, CB, $\mathrm{LH}$, and $\mathrm{MH}$ commented on the manuscript. All authors read and approved the last version of the manuscript.

\section{Funding}

The MOTAR study was funded by NWO VICl grant number 91811602 of B.W.J.H. Penninx. NWO had no role in the design of the study, the collection, analysis and interpretation of the data, or in the preparation, review, or approval of the manuscript.

\section{Availability of data and materials}

MOTAR-data can be requested through the submission of an analysis plan. Instructions can be found on the website www.motar.nl

\section{Ethics approval and consent to participate}

Ethical and professional guidelines will be followed at all times, in line with Good Clinical Practice guidelines. Institutional review board approval has been obtained from the Medical Ethics Committee of VU Medical Centre Amsterdam, the Netherlands (May 23, 2012, VUmc METC registration number: 2012-064). All participants gave written informed consent prior to baseline assessment. The MOTAR study was registered in the Trial register of The Netherlands: Trialregister.nl, Number of identification: NTR3460.

\section{Consent for publication}

Not applicable.

\section{Competing interests}

BP has received (non-related) funding from Jansen Research and Boehringer Ingelheim. All other authors declare that they have no conflicts of interest.

Received: 3 June 2019 Accepted: 11 December 2019

Published online: 30 December 2019

\section{References}

1. Murray CJ, Lopez AD. Alternative projections of mortality and disability by cause 1990-2020: global burden of disease study. Lancet. 1997;349:1498-504

2. Ferrari AJ, Charlson FJ, Norman RE, Patten SB, Freedman G, Murray CJ, et al. Burden of depressive disorders by country, sex, age, and year: findings from the global burden of disease study 2010. PLoS Med. 2013;10:e1001547.

3. Penninx BW, Milaneschi Y, Lamers F, Vogelzangs N. Understanding the somatic consequences of depression: biological mechanisms and the role of depression symptom profile. BMC Med. 2013;11:129.

4. Roy-Byrne PP, Davidson KW, Kessler RC, Asmundson GJ, Goodwin RD, Kubzansky L, et al. Anxiety disorders and comorbid medical illness. Gen Hosp Psychiatry. 2008;30:208-25.

5. Barnes DE, Alexopoulos GS, Lopez OL, Williamson JD, Yaffe K. Depressive symptoms, vascular disease, and mild cognitive impairment: findings from the cardiovascular health study. Arch Gen Psychiatry. 2006;63:273-9.

6. Black CN, Bot M, Scheffer PG, Cuijpers P, Penninx BW. Is depression associated with increased oxidative stress? A systematic review and metaanalysis. Psychoneuroendocrinology. 2015;51:164-75.

7. Dowlati Y, Herrmann N, Swardfager W, Liu H, Sham L, Reim EK, et al. A metaanalysis of cytokines in major depression. Biol Psychiatry. 2010;67:446-57.

8. Blumenthal JA, Babyak MA, Doraiswamy PM, Watkins L, Hoffman BM Barbour KA, et al. Exercise and pharmacotherapy in the treatment of major depressive disorder. Psychosom Med. 2007;69:587-96.

9. Kirsch I, Deacon BJ, Huedo-Medina TB, Scoboria A, Moore TJ, Johnson BT. Initial severity and antidepressant benefits: a meta-analysis of data submitted to the Food and Drug Administration. PLoS Med. 2008;5:e45.

10. Mead GE, Morley W, Campbell P, Greig CA, McMurdo M, Lawlor DA. Exercise for depression. Cochrane Database Syst Rev. 2009:CD004366.

11. Netz Y. Is the comparison between exercise and pharmacologic treatment of depression in the clinical practice guideline of the American College of Physicians Evidence-Based? Front Pharmacol. 2017;8:257.

12. Puterman E, Lin J, Blackburn E, O'Donovan A, Adler N, Epel E. The power of exercise: buffering the effect of chronic stress on telomere length. PLoS One. 2010;5:e10837.
13. Ridout KK, Ridout SJ, Price LH, Sen S, Tyrka AR. Depression and telomere length: a meta-analysis. J Affect Disord. 2016;191:237-47.

14. Darrow SM, Verhoeven JE, Révész D, Lindqvist D, Penninx BWJH, Delucchi $\mathrm{KL}$, Wolkowitz OM, Mathews CA. The association between psychiatric disorders and telomere length. Psychosom Med. 2016;78:776-87.

15. Verhoeven JE, Révész D, Epel ES, Lin J, Wolkowitz OM, Penninx BWJH, Révész D, Epel ES, Lin J, Wolkowitz OM, Penninx BWJH. Major depressive disorder and accelerated cellular aging: results from a large psychiatric cohort study. Mol.Psychiatry. 2014;19:895-901.

16. Verhoeven JE, Révész D, van Oppen P, Epel ES, Wolkowitz O, Penninx BWJH. Anxiety disorders and accelerated cellular aging. Br J Psychiatry. 2014;206(5):371-8.

17. Muezzinler A, Zaineddin AK, Brenner H. A systematic review of leukocyte telomere length and age in adults. Ageing Res Rev. 2013;12:509-19.

18. Wang Q, Zhan Y, Pedersen NL, Fang F, Hägg S. Telomere length and allcause mortality: a meta-analysis. Ageing Res Rev. 2018, Dec:48:11-20.

19. Blackburn EH. Switching and signaling at the telomere. Cell. 2001;106:661-73.

20. Cawthon RM, Smith KR, O'Brien E, Sivatchenko A, Kerber RA. Association between telomere length in blood and mortality in people aged 60 years or older. Lancet. 2003:361:393-5.

21. D'Mello MJ, Ross SA, Briel M, Anand SS, Gerstein H, Pare G. Association between shortened leukocyte telomere length and cardiometabolic outcomes: systematic review and meta-analysis. Circ Cardiovasc Genet. 2015;8:82-90.

22. Haycock PC, Heydon EE, Kaptoge S, Butterworth AS, Thompson A, Willeit P. Leucocyte telomere length and risk of cardiovascular disease: systematic review and meta-analysis. BMJ. 2014;349:94227.

23. Wolkowitz OM, Mellon SH, Epel ES, Lin J, Reus VI, Rosser R, et al. Resting leukocyte telomerase activity is elevated in major depression and predicts treatment response. Mol Psychiatry. 2012;17:164-72.

24. Epel ES, Blackburn EH, Lin J, Dhabhar FS, Adler NE, Morrow JD, et al. Accelerated telomere shortening in response to life stress. Proc Natl Acad Sci U S A. 2004;101:17312-5.

25. Han LKM, Verhoeven JE, Tyrka A, Penninx BWJH, Wolkowitz OM, Månsson KNT, Lindqvist D, Vinkers CH, Boks MP, Révész D, Mellon SH, Picard M. Accelerating research on biological aging and mental health. Psychoneuroendocrinology. 2019;106:293-311.

26. Howren MB, Lamkin DM, Suls J. Associations of depression with C-reactive protein, IL-1, and IL-6: a meta-analysis. Psychosom Med. 2009;71:171-86.

27. Hoge EA, Brandstetter K, Moshier S, Pollack MH, Wong KK, Simon NM. Broad spectrum of cytokine abnormalities in panic disorder and posttraumatic stress disorder. Depress Anxiety. 2009;26:447-55.

28. Stetler C, Miller GE. Depression and hypothalamic-pituitary-adrenal activation: a quantitative summary of four decades of research. Psychosom Med. 2011;73:114-26.

29. Fisher AJ, Newman MG. Heart rate and autonomic response to stress after experimental induction of worry versus relaxation in healthy, high-worry, and generalized anxiety disorder individuals. Biol Psychol. 2013;93:65-74.

30. Kemp AH, Quintana DS, Gray MA, Felmingham KL, Brown K, Gatt JM. Impact of depression and antidepressant treatment on heart rate variability: a review and meta-analysis. Biol Psychiatry. 2010:67:1067-74.

31. Ghanei Gheshlagh R, Parizad N, Sayehmiri K. The relationship between depression and metabolic syndrome: systematic review and meta-analysis study. Iran Red Crencent Med J. 2016;15:18(6)

32. Carrero JJ, Stenvinkel P, Fellstrom B, Qureshi AR, Lamb K, Heimburger O, et al. Telomere attrition is associated with inflammation, low fetuin-a levels and high mortality in prevalent haemodialysis patients. J Intern Med. 2008;263:302-12.

33. Revesz D, Verhoeven JE, Milaneschi Y, de Geus EJCN, Wolkowitz OM, Penninx BWJH. Dysregulated physiological stress systems and accelerated cellular aging. Neurobiol Aging. 2014;35:1422-30

34. Revesz D, Verhoeven JE, Milaneschi Y, Penninx BWJH. Depressive and anxiety disorders and short leukocyte telomere length: mediating effects of metabolic stress and lifestyle factors. Psychol Med. 2016;46(11):2337-49.

35. Muscatell KA, Dedovic K, Slavich GM, Jarcho MR, Breen EC, Bower JE, et al. Greater amygdala activity and dorsomedial prefrontal-amygdala coupling are associated with enhanced inflammatory responses to stress. Brain Behav Immun. 2015;43:46-53.

36. Satizabal CL, Zhu YC, Mazoyer B, Dufouil C, Tzourio C. Circulating IL-6 and CRP are associated with MRI findings in the elderly: the 3C-Dijon study. Neurology. 2012;78:720-7.

37. Slavich GM, Way BM, Eisenberger NI, Taylor SE. Neural sensitivity to social rejection is associated with inflammatory responses to social stress. Proc Natl Acad Sci U S A. 2010;107:14817-22. 
38. van Velzen LS, Wijdeveld M, Black CN, van Tol MJ, van der Wee NJA, Veltman DJ, et al. Oxidative stress and brain morphology in individuals with depression, anxiety and healthy controls. Prog Neuro-Psychopharmacol Biol Psychiatry. 2017;76:140-4.

39. Kremen WS, O'Brien RC, Panizzon MS, Prom-Wormley E, Eaves LJ, Eisen SA, et al. Salivary cortisol and prefrontal cortical thickness in middle-aged men: a twin study. Neuroimage. 2010;53:1093-102.

40. Bora E, Harrison BJ, Davey CG, Yucel M, Pantelis C. Meta-analysis of volumetric abnormalities in cortico-striatal-pallidal-thalamic circuits in major depressive disorder. Psychol Med. 2012;42:671-81.

41. Koolschijn PC, van Haren NE, Lensvelt-Mulders GJ, Hulshoff Pol HE, Kahn RS. Brain volume abnormalities in major depressive disorder: a meta-analysis of magnetic resonance imaging studies. Hum Brain Mapp. 2009;30:3719-35.

42. Schmaal L, Veltman DJ, Van Erp TG, Samann PG, Frodl T, Jahanshad N, et al. Subcortical brain alterations in major depressive disorder: findings from the ENIGMA major depressive disorder working group. Mol Psychiatry. 2016;21:806-12.

43. Schmaal L, Hibar DP, Samann PG, Hall GB, Baune BT, Jahanshad N, et al. Cortical abnormalities in adults and adolescents with major depression based on brain scans from 20 cohorts worldwide in the ENIGMA major depressive disorder working Group17. Mol Psychiatry. 2017;22:900-9.

44. van Tol ML, van der Wee NJA, van den Heuvel OA, Nielen MMA, Demenescu LR, Aleman A, et al. Regional brain volume in depression and anxiety disorders. Arch Gen Psychiatry. 2010;67(10):1002-11.

45. Videbech P, Ravnkilde B. Hippocampal volume and depression: a metaanalysis of MRI studies. Am J Psychiatry. 2004;161:1957-66.

46. Rive MM, van Rooijen G, Veltman DJ, Philips ML, Schene AH, Ruhe HG. Neural correlates of dysfunctional emotion regulation in major depressive disorder. A systematic review of neuroimaging studies. Neurosci Biobehav Rev. 2013;37:2529-53.

47. Jaworska N, Yang XR, Knott $V$, MacQueen G. A review of fMRI studies during visual emotive processing in major depressive disorder. World J Biol Psychiatry. 2015;16(7):446-71

48. Bruhl AB, Hanggi J, Baur V, Rufer M, Delsignore A, Weidt S, Jancke L, Herwig $U$. Increased cortical thickness in a frontoparietal network in social anxiety disorder. Hum Brain Mapp. 2014;35(7):2966-77.

49. Hattingh CJ, Ipser J, Tromp SA, Syal S, Lochner C, Brooks SJ, Stein DJ. Functional magnetic resonance imaging during emotion recognition in social anxiety disorder: an activation likelihood meta-analysis. Front Hum Neurosci. 2013;6:347.

50. Müller VI, Cieslik EC, Serbanescu I, Laird AR, Fox PT, Eickhoff SB. Altered brain activity in unipolair depression revisited: meta-analyses of neuroimaging studies. JAMA Psychiatry. 2017;74(1):47-55.

51. Cipriani A, Furukawa TA, Salanti G, Chaimani A, Atkinson LZ, Ogawa Y, Leucht S, Ruhe HG, Turner EH, Higgins JPT, Egger M, Takeshima N, Hayasaka Y, Imai H, Shinohara K, Tajika A, Ionnidis JPA, Geddes JR. Comparative efficacy and acceptability of 21 antidepressant drugs for the acute treatment of adults with major depressive disorder: a systematic review and network meta-analysis. Lancet. 2018;391(10128):1357-66.

52. Vythilingam M, Vermetten $E$, Anderson GM, Luckenbaugh D, Anderson ER, Snow J, et al. Hippocampal volume, memory, and cortisol status in major depressive disorder: effects of treatment. Biol Psychiatry. 2004;56:101-12.

53. Hernandez ME, Mendieta D, Martinez-Fong D, Loria F, Moreno J, Esrada I, et al. Variations in circulating cytokine levels during 52 week course of treatment with SSRI for major depressive disorder. Eur Neuropsychopharmacol. 2008;18:917-24.

54. Khanzode SD, Dakhale GN, Khanzode SS, Saoji A, Palasodkar R. Oxidative damage and major depression: the potential antioxidant action of selective serotonin re-uptake inhibitors. Redox Rep. 2003;8:365-70.

55. Bersani FS, Lindqvist D, Mellon SH, Penninx BW, Verhoeven JE, Revesz D, et al. Telomerase activation as a possible mechanism of action for psychopharmacological interventions. Drug Discov Today. 2015;20:1305-9.

56. Hough CM, Bersani FS, Mellon SH, Epel ES, Reus VI, Lindqvist D, et al. Leukocyte telomere length predicts SSRI response in major depressive disorder: a preliminary report. Mol Neuropsychiatry. 2016;2:88-96.

57. Martinsson L, Wei $Y, X u$ D, Melas PA, Mathe AA, Schalling M, et al. Longterm lithium treatment in bipolar disorder is associated with longer leukocyte telomeres. Transl Psychiatry. 2013;3:e261.

58. Herring MP, Jacob ML, Suveg C, Dishman RK, O'Connor PJ. Feasibility of exercise training for the short-term treatment of generalized anxiety disorder: a randomized controlled trial. Psychother Psychosom. 2011;81:21-8.
59. Wolff E, Gaudlitz K, von Lindenberger BL, Plag J, Heinz A, Strohle A. Exercise and physical activity in mental disorders. Eur Arch Psychiatry Clin Neurosci. 2011;261(Suppl 2):186-91.

60. Jarvekulg A, Viru A. Opioid receptor blockade eliminates mood effects of aerobic gymnastics. Int J Sports Med. 2002;23:155-7.

61. Schwarz L, Kindermann W. Changes in beta-endorphin levels in response to aerobic and anaerobic exercise. Sports Med. 1992;13:25-36.

62. Dishman RK. Brain monoamines, exercise, and behavioral stress: animal models. Med Sci Sports Exerc. 1997;29:63-74.

63. Seifert $T$, Rasmussen $P$, Brassard $P$, Homann PH, Wissenberg M, Nordby $P$, et al. Cerebral oxygenation and metabolism during exercise following three months of endurance training in healthy overweight males. Am J Phys Regul Integr Comp Phys. 2009;297:R867-76.

64. Nojima H, Watanabe $H$, Yamane K, Kitahara Y, Sekikawa K, Yamamoto H, et al. Effect of aerobic exercise training on oxidative stress in patients with type 2 diabetes mellitus. Metabolism. 2008;57:170-6.

65. Goldhammer E, Tanchilevitch A, Maor I, Beniamini Y, Rosenschein U, Sagiv M. Exercise training modulates cytokines activity in coronary heart disease patients. Int J Cardiol. 2005;100:93-9.

66. Nicklas BJ, Hsu FC, Brinkley TJ, Church T, Goodpaster BH, Kritchevsky SB, et al. Exercise training and plasma $C$-reactive protein and interleukin-6 in elderly people. J Am Geriatr Soc. 2008;56:2045-52.

67. You T, Nicklas BJ. Effects of exercise on adipokines and the metabolic syndrome. Curr Diab Rep. 2008;8:7-11.

68. Karacabey K. The effect of exercise on leptin, insulin, cortisol and lipid profiles in obese children. J Int Med Res. 2009;37:1472-8.

69. Ornish D, Lin J, Daubenmier J, Weidner G, Epel E, Kemp C, et al. Increased telomerase activity and comprehensive lifestyle changes: a pilot study. Lancet Oncol. 2008;9:1048-57.

70. Du M, Prescott J, Kraft P, Han J, Giovannucci E, Hankinson SE, et al. Physical activity, sedentary behavior, and leukocyte telomere length in women. Am J Epidemiol. 2012;175:414-22.

71. Osthus IB, Sgura A, Berardinelli F, Alsnes IV, Bronstad E, Rehn T, et al. Telomere length and long-term endurance exercise: does exercise training affect biological age? A pilot study. PLoS One. 2012;7:e52769.

72. Puterman E, Lin J, Krauss J, Blackburn EH, Epel ES. Determinants of telomere attrition over 1 year in healthy older women: stress and health behaviors matter. Mol Psychiatry. 2015;20:529-35.

73. Blumenthal JA, Babyak MA, Moore KA, Craighead WE, Herman S, Khatri $P$, et al. Effects of exercise training on older patients with major depression. Arch Intern Med. 1999;159:2349-56.

74. Carek PJ, Laibstain SE, Carek SM. Exercise for the treatment of depression and anxiety. Int J Psychiatry Med. 2011;41:15-28.

75. Lamers F, van Oppen P, Comijs HC, Smit JH, Spinhoven P, van Balkom AJ, Nolen WA, Zitman FG, Beekman AT, Penninx BW. Comorbidity patterns of anxiety and depressive disorders in a large cohort study: the Netherlands study of depression and anxiety (NESDA). J Clin Psychiatry. 2011;72(3):341-8.

76. Verduijn J, Verhoeven J, Milaneschi Y, Schoevers RA, van Hemert AM, Beekman ATF, Penninx BWJH. Reconsidering the prognosis of major depressive disorder across diagnostic boundaries: full recovery is the exception rather than the rule. BMC Med. 2017;15(1):215.

77. Scholten WD, Batelaan NM, Penninx BW, van Balkom AJ, Smit JH, Schoevers RA, van Oppen P. Diagnostic instability of recurrence and the impact on recurrence rates in depressive and anxiety disorders. J Affect Disord. 2016;195:185-90.

78. Strawn JR, Welge JA, Wehry AM, Keeshin BR, Rynn MA. Efficacy and tolerability of antidepressants in pediatric anxiety disorders: a systematic review and meta-analysis. Depress Anxiety. 2015;32(3):149-57.

79. Lambert ME, Wood J. Incorporating patient preferences into randomized trails. J Clin Epidemiol. 2000;53(2):163-6.

80. Wittchen HU. Reliability and validity studies of the WHO--composite international diagnostic interview (CIDI): a critical review. J Psychiatr Res. 1994;28:57-84.

81. Lyketsos CG, Nestadt G, Cwi J, Heithoff K, Eaton WW. The life-chart method to describe the course of psychopathology. Int J Methods Psychiatr Res. 1994:4:143-55.

82. Rush AJ, Gullion CM, Basco MR, Jarrett RB, Trivedi MH. The Inventory of Depressive Symptomatology (IDS): psychometric properties. Psychol Med. 1996;26:477-86.

83. Beck AT, Epstein N, Brown G, Steer RA. An inventory for measuring clinical anxiety: psychometric properties. J Consult Clin Psychol. 1988;56:893-7. 
84. Marks IM, Mathews AM. Brief standard self-rating for phobic patients. Behav Res Ther. 1979;17:263-7.

85. Levine DW, Kripke DF, Kaplan RM, Lewis MA, Naughton MJ, Bowen DJ, et al. Reliability and validity of the Women's Health Initiative Insomnia Rating Scale. Psychol Assess. 2003;15:137-48.

86. Wendel-Vos GC, Schuit AJ, Saris WH, Kromhout D. Reproducibility and relative validity of the short questionnaire to assess health-enhancing physical activity. J Clin Epidemiol. 2003;56:1163-9.

87. Saunders JB, Aasland OG, Babor TF, de la Fuente JR, Grant M. Development of the Alcohol Use Disorders Identification Test (AUDIT): WHO collaborative project on early detection of persons with harmful alcohol consumption-II. Addiction. 1993;88:791-804.

88. Meadows G, Harvey C, Fossey E, Burgess P. Assessing perceived need for mental health care in a community survey: development of the Perceived Need for Care Questionnaire (PNCQ). Soc Psychiatry Psychiatr Epidemiol. 2000;35:427-35.

89. Hakkart-van Rooijen L. Trimbos/iMTA questionnaire for costs associated with psychiatric illness (TIC-P). Institute for Medical Technology Assessment: Rotterdam; 2002

90. Costa PT Jr, McCrae RR. Domains and facets: hierarchical personality assessment using the revised NEO personality inventory. J Pers Assess. 1995;64:21-50

91. Pearlin LI, Schooler C. The structure of coping. J Health Soc Behav. 1978;19:2-21.

92. Van der Does W. Cognitive reactivity to sad mood: structure and validity of a new measure. Behav Res Ther. 2002;40:105-20.

93. Peterson RA, Reiss S. Anxiety sensitivity index. Wortington: International Diagnostic Systems Publishing Corporation; 1992.

94. Greenwald AG, McGhee DE, Schwartz JL. Measuring individual differences in implicit cognition: the implicit association test. J Pers Soc Psychol. 1998;74:1464-80.

95. Van der Heijden P, van den Bos P, Mol B, Kessels RP. Structural validity of the Dutch-language version of the WAIS-III in a psychiatric sample. Appl Neuropsychol Adult. 2013;20(1):41-6.

96. Brugha TS, Cragg D. The list of threatening experiences: the reliability and validity of a brief life events questionnaire. Acta Psychiatr Scand. 1990;82:77-81.

97. Bernstein DP, Stein JA, Newcomb MD, Walker E, Pogge D, Ahluvalia T, et al. Development and validation of a brief screening version of the childhood trauma questionnaire. Child Abuse Negl. 2003;27:169-90.

98. Rey A. Clinical psychology; theoretical and practical aspects. Arch Psycol Neurol Psychiatr. 1953;14:16-38.

99. Hariri AR, Bookheimer SY, Mazziotta JC. Modulating emotional responses: effects of a neocortical network on the limbic system. Neuroreport. 2000;11(1):43-8

100. Jaeggi SM, Buschkuehi M, Perrig WJ, Meier B. The concurrent validity of the N-back task as a working memory measure. Memory. 2010;18(4): 394-412.

101. Pizzi C, Mancini S, Angeloni L, Fontana F, Manzoli L, Costa GM. Effects of selective serotonin reuptake inhibitor therapy on endothelial function and inflammatory markers in patients with coronary heart disease. Clin Pharmacol Ther. 2009;86:527-32.

102. Dod HS, Bhardwaj R, Sajja V, Weidner G, Hobbs GR, Konat GW, et al. Effect of intensive lifestyle changes on endothelial function and on inflammatory markers of atherosclerosis. Am J Cardiol. 2010;105:362-7.

103. Rethorst CD, Wipfli BM, Landers DM. The antidepressive effects of exercise: a meta-analysis of randomized trials. Sports Med. 2009;39:491-511.

104. SFK. Data en feiten 2017. Het jaar 2016 in cijfers. Den Haag: Stichting Farmaceutische Kengetallen; 2017. ISBN 978-90-817780-6-0. https://www. sfk.nl/publicaties/data-en-feiten/data-en-feiten-2017

105. Department of Health and Human Services Website. Physical activity guidelines for Americans. 2008. Electronic citation.

106. Dunn AL, Trivedi MH, Kampert JB, Clark CG, Chambliss HO. Exercise treatment for depression: efficacy and dose response. Am J Prev Med. 2005;28:1-8

107. Karvonen MJ, Kentala E, Mustala O. The effects of training on heart rate; a longitudinal study. Ann Med Exp Biol Fenn. 1957;35:307-15.

108. Le Nguyen K, Lin J, Algoe SB, Branley NM, Kim SL, Branley J, Salzberg S, Frederin BL. Loving-kindness meditation slows biological aging in noviced: evidence from a 12-week randomised controlled trail. Psychoneuroendrocrinology. 2019;108:20-7.
109. Conklin QA, King BG, Zanesco AP, Lin J, Hamidi AB, Pokorny JJ, AlvarezLopez MJ, Cosin-Tomas M, Huang C, Kaliman P, Epel ES, Saron CD. Insigth meditation and telomere biology: the effects of intensive retreat and the moderating role of personality. Brain Behav Immun. 2018;70: 233-45.

110. de Geus EJ, Willemsen GH, Klaver $\mathrm{CH}$, van Doornen $\sqcup$. Ambulatory measurement of respiratory sinus arrhythmia and respiration rate. Bio Psychol. 1995;41:205-27.

111. Vancampfort D, Guelinckx H, De Hert M, Stubbs B, Soundy A, Rosenbaum S, De Schepper E, Probst M. Reliability and clinical correlates of the Astrandrhyming sub-maximal exercise test in patients with schizophrenia or schizoaffective disorder. Psychiatry Res. 2014;220(3):778-83.

112. Roberts HC, Denison HJ, Martin HJ, Patel HP, Sydall H, Cooper C, et al. A review of the measurements of grip strength in clinical and epidemiological studies: towards a standardized approach. Age Aging. 2011:40(4):423-9.

113. Quanjer PH, Lebowitz MD, Gregg I, Miller MR, Pederson OF. Peak expiratory flow: conclusions and recommendations of a working party of the european respiratory society. Eur Respir J Suppl. 1997;24:2s-8s.

114. Von KM, Ormel J, Keefe FJ, Dworkin SF. Grading the severity of chronic pain Pain. 1992;50:133-49.

115. Terluin B, van Marwijk HW, Ader HJ, de Vet HC, Penninx BW, Hermens ML, et al. The four-dimensional symptom questionnaire (4DSQ): a validation study of a multidimensional self-report questionnaire to assess distress, depression, anxiety and somatization. BMC Psychiatry. 2006;6:34.

116. Chwastiak LA, Von Korff M. Disability in depression and back pain: evaluation of the World Health Organization Disability Assessment Schedule (WHO DAS II) in a primary care setting. J Clin Epidemiol. 2003;56:507-14.

117. Thirion B, Pinel P, Meriaux S, Roche A, Dehaene S, Poline JB. Analysis of a large fMRI cohort: statistical and methodological issues for group analyses. Neuroimage. 2007;35:105-20.

\section{Publisher's Note}

Springer Nature remains neutral with regard to jurisdictional claims in published maps and institutional affiliations.

Ready to submit your research? Choose BMC and benefit from:

- fast, convenient online submission

- thorough peer review by experienced researchers in your field

- rapid publication on acceptance

- support for research data, including large and complex data types

- gold Open Access which fosters wider collaboration and increased citations

- maximum visibility for your research: over $100 \mathrm{M}$ website views per year

At $\mathrm{BMC}$, research is always in progress.

Learn more biomedcentral.com/submission 